\title{
Cristianismo y Sociedad (1963-1973). Protestantismo de izquierda en la historia reciente de América Latina
}

\section{Cristianismo y Sociedad (1963-1973). Protestantism of the Left in the Recent History of Latin America}

\begin{abstract}
Resumen
El objetivo de este artículo es caracterizar la primera etapa de la revista Cristianismo y Sociedad entre los años 1963 y 1973. La revista fue la principal publicación periódica de Iglesia y Sociedad en América Latina (ISAL), un agrupamiento político religioso vinculado al protestantismo que a principios de la década del sesenta se asoció a un proceso de radicalización de la vida cultural y política del continente. En su primera época fue impresa en Montevideo y distribuida desde allí para toda la región. A partir del golpe de Estado en Uruguay en 1973, comenzó a editarse en Buenos Aires bajo el sello de la editorial Tierra Nueva hasta 1980.

En el primer apartado, se describe al agrupamiento político religioso de ISAL como una expresión del protestantismo de izquierdas latinoamericano y a los sujetos que conformaron la junta editorial que llevó adelante la revista. En el segundo apartado, se analizan aspectos materiales vinculados al diseño, la producción y distribución de la revista. Finalmente, se señalan temas y autores que conformaron la política editorial de la publicación en esta primera etapa.
\end{abstract}

Palabras claves protestantismo, izquierdas, revistas, América Latina, teología de la liberación, secularización 


\begin{abstract}
The objective of this article is to characterize the first stage of the magazine Cristianismo $y$ Sociedad between 1963 and 1973. The magazine was the main periodical publication of Iglesia y Sociedad en América Latina (ISAL), a religious political grouping linked to Protestantism that in the beginning of the sixties was associated with a process of radicalization of the cultural and political life of the continent. In its first period it was printed in Montevideo and distributed from there to the whole continent. After the putsch in Uruguay in 1973, it began to be published in Buenos Aires under the stamp of the publisher Tierra Nueva until 1980. In the first section, is described the religious and political grouping of ISAL as an expression of Latin American left Protestantism and the subjects that formed the editorial board that led the magazine. In the second section, are analyzed material aspects related to the design, production and distribution of the journal. Finally, are indicated themes and authors that shaped the editorial policy of the publication in this first stage.
\end{abstract}

Keywords

Protestantism, lefts, magazines, Latin America, liberation theology, secularization

\title{
Introducción
}

La revista Cristianismo y Sociedad $(C y S)$ fue una publicación periódica producida por Iglesia y Sociedad en América Latina (ISAL), un agrupamiento político religioso vinculado al protestantismo que a principios de la década del sesenta se asoció a un proceso de radicalización de la vida cultural y política del continente. En el ciclo de vida de la revista pueden identificarse al menos dos etapas: la primera época desarrollada por ISAL en Montevideo que incluye del $\mathrm{N}^{\circ} 1$ al N³8 (1963-1973) y una segunda época emprendida por la editorial Tierra Nueva desde Buenos Aires que abarca del N³9 al N63 (1974-1980). Sin embargo, hay indicios de que la revista fue continuada en otras ciudades a partir de iniciativas vinculadas a asociaciones protestantes: Santo Domingo (1981-1982), México (1983-1995) y Guayaquil (1996-1999).

CyS puede inscribirse dentro de dos tradiciones de publicaciones periódicas latinoamericanas en el siglo XX, diacrónica y sincrónicamente. Para el primer caso, forma parte de una rica historia de edición de revistas protestantes en el Río de la Plata. El protestantismo desde sus orígenes en la reforma del siglo XVI encontró 
en la edición de panfletos, sermones y biblias un modo de difundir el evangelio y las nuevas doctrinas impulsadas por referentes teológicos (Cameron 178; Gilmont 376). La producción rioplatense de revistas protestantes se inició a fines del siglo XIX. Dos publicaciones periódicas son significativas de este período: $E l$ Evangelista, iniciada en 1877 en Montevideo; y de El Estandarte Evangélico, iniciada en 1883 en Buenos Aires. Por su parte, durante la primera mitad del siglo XX, cabe destacar revistas tales como La Nueva Democracia y La Reforma (circa 1930), El Predicador Evangélico (1943) y Cuadernos Teológicos (1950-1967) editadas en la capital argentina. Mientras que en Uruguay fueron relevantes publicaciones vinculadas a la iglesia metodista, como el periódico La Idea (19171957) y la revista para la infancia evangélica Arco Iris (1948-1963).

Asimismo, es preciso ubicar a $C y S$ en su propio tiempo de los años sesenta. En este caso, la revista se emparentaba a un conjunto de publicaciones periódicas de la denominada nueva izquierda que incluían un espectro amplio de organizaciones heterogéneas desde el punto de vista político y cultural (Lenci y Barletta 177). Entre ellas se destacaron en Argentina publicaciones tales como Antropología del Tercer Mundo, Envido, Che, Pasado y Presente, Los Libros, entre otras. Y en el caso de Uruguay, el semanario Marcha (1939-1974) y Época (19621967). Estas revistas eran concebidas como un instrumento de intervención político-intelectual a medio camino entre el libro y el panfleto (Girbal-Blacha y Quatrocchi-Woisson 23). En este sentido, los sesenta fueron escenario de una vasta proliferación editorial emprendida por diversas organizaciones del campo político e intelectual. Las revistas no significaron meramente órganos de expresión de ideas y posiciones respecto a los temas de agenda política, sino que además contribuyeron de modo sustantivo a construir la identidad de estas organizaciones (Spivak 16).

Dentro de este conjunto de revistas político-culturales, también pueden distinguirse aquellas pertenecientes a sectores religiosos que buscaron dialogar con las izquierdas y el pensamiento marxista. Dentro del catolicismo se reconocen en Argentina la revista Cristianismo y Revolución (1966-1971) y en Uruguay la revista Víspera (1967-1973), perteneciente al Movimiento Internacional de Estudiantes 
Católicos con sede en Montevideo. Para el caso de revistas asociadas al protestantismo de izquierda, fueron estudiadas publicaciones tales como Christianity and Crisis Magazine (1941-1993) para el caso de los Estados Unidos (Hulsether), o la revista Paz e Terra (1966-1969) en Brasil (Pimentel). Por su parte, CyS fue analizada en el período circunscripto a los años 1970-1975 como parte de una investigación más amplia sobre redes de coautoría ecuménicas de sumo interés para comprender sus conexiones trasnacionales del protestantismo (Paredes). Sin embargo, la revista no ha sido aún considerada como objeto en sí mismo dando cuenta de su propia historicidad, materialidad y política editorial en contexto.

En el presente artículo, se describe y analiza la primera etapa de $C y S$ a fin de dar cuenta de la red política e intelectual en la que se inscribía; de aspectos materiales vinculados al diseño, la producción y la circulación; como así también de los debates intelectuales que se tejieron desde sus páginas. ${ }^{1}$ El argumento principal que aquí se sostiene es que $C y S$ no sólo significó el órgano de difusión de las ideas de una agrupación política religiosa como ISAL, sino que, en tanto formación cultural, contribuyó a articular un proceso social más amplio asociado a la gestación de un protestantismo de izquierda y a la secularización de la sociedad en la historia reciente de América Latina.

El protestantismo de izquierda configuró una particular conjunción entre religión y sociedad operando un desplazamiento dentro del campo religioso que es posible inscribir en la larga duración del proceso de secularización del mundo occidental. Como argumenta Roberto Di Stefano (4), la secularización fue un proceso histórico en el cual la religión perdió su carácter regulador de la sociedad. Es decir, los comportamientos de los sujetos ganaron autonomía respecto de la autoridad religiosa. Esto no implicó la desaparición de la religión en las sociedades occidentales sino más bien un "tránsito de los regímenes de cristiandad a los de

${ }^{1}$ Los ejemplares de la revista fueron consultados en la biblioteca del ex ISEDET ubicada en el barrio de Flores de Buenos Aires (Argentina) y en el Archivo Piquinela, perteneciente a la Iglesia Metodista Central, Montevideo (Uruguay). 
modernidad religiosa" en el cual se produce "una permanente recreación de las identidades religiosas que ese tránsito ha puesto en movimiento" (Di Stefano 5). Bajo esta perspectiva, al desarrollar prácticas propias del mundo secular y tomar distancia de las autoridades eclesiásticas, los protestantes que editaron $C y S$ recrearon y reafirmaron su identidad como cristianos tanto dentro de sus propias comunidades confesionales como en el campo de las izquierdas continentales.

\section{CyS en la construcción de un protestantismo de izquierda en América Latina}

Como sostiene María Teresa Gramuglio (194) las revistas resultan una "fuente segura" en su materialidad para analizar grupos, redes y figuras de la vida intelectual moderna. Las revistas, en tanto formaciones culturales, permiten identificar los proyectos de diversos colectivos con vocación de generar un tipo de opinión específica dentro de un campo particular. Sin embargo, como argumenta Verónica Delgado (14) las publicaciones periódicas deben ser analizadas como parte de un proceso cultural más amplio que contribuyen a forjar desde sus discursos e interacciones. En este apartado, se caracteriza a $C y S$ como el principal proyecto editorial de ISAL que contribuyó a construir la identidad de un protestantismo de izquierda en América Latina.

A partir de mediados del siglo XX, la posguerra en Europa y las transformaciones que estaban viviendo los países del denominado Tercer Mundo, conllevó una serie de discusiones y construcciones novedosas en el mundo protestante a escala global. En primer lugar, la creación del Consejo Mundial de Iglesias (CMI) en 1948 con sede en Ginebra (Suiza), una organización ecuménica internacional que integró un amplio conjunto de confesiones del mundo evangélico (luteranos, anglicanos, valdenses, metodistas, baptistas, entre otros). ${ }^{2}$ Esta organización estaba particularmente interpelada ante los denominados "rápidos cambios sociales" que estaba viviendo el "tercer mundo". De hecho, el CMI

\footnotetext{
${ }^{2}$ Sobre historia del CMI véase: https://www.oikoumene.org/es/about-us/history
} 
financió a fines de la década del cincuenta una serie de investigaciones dirigidas por Egbert De Vries y Paul Abrecht a fin de realizar diagnósticos sobre transformaciones sociales a nivel global. Asimismo, apoyó la conformación de grupos evangélicos en Asia, África y América Latina -entre ellos ISALpreocupados por la "responsabilidad de los cristianos" en la vida política y social de sus continentes. Un primer libro editado por ISAL daba cuenta de esta categoría central de "responsabilidad" que con el tiempo tomó un cariz más radicalizado asociado al "compromiso" por las causas revolucionarias (Obermüller et al. 1).

ISAL se desarrolló como agrupamiento político y religioso entre los años 1961 y 1975, configurando vínculos novedosos entre protestantismo, política y pensamiento de izquierda a partir de una fuerte impronta de formación intelectual y producción de publicaciones. Si bien el núcleo principal de sus integrantes estaba en la ciudad de Montevideo, constituía una red de alcances trasnacionales tanto a escala continental como global. Estuvo estrechamente ligada al $C M I$ en tanto fue promovido e impulsado desde allí. El CMI organizó en 1961 la "1 Consulta Latinoamericana de Iglesia y Sociedad" en la ciudad de Huampaní (cerca de Lima, Perú) en donde se constituyó la Junta Latinoamericana de Iglesia y Sociedad (JLAIS) que fue el organismo rector de ISAL integrado por miembros de distintas iglesias evangélicas de todo el continente, entre otros: Julio de Santa Ana, Emilio Castro, Hiber Conteris, Luis Odell, y posteriormente, Julio Barreiro (Uruguay), Mauricio López y José Miguez Bonino (Argentina); Rubem Alves, Waldo César y Hugo Assman (Brasil); Gerardo Pet y Pedro Negre Rigol (Bolivia); Richard Shaull (Estados Unidos); Fernando Augusto Arlt y Christian Lalive D’Epinay (Chile). ${ }^{3}$

Es posible distinguir al menos tres etapas en el ciclo de desarrollo del movimiento de ISAL: una primera etapa entre 1961 y 1966 donde se inicia el movimiento y sus programas de estudios y publicaciones. Una segunda etapa; entre 1966 y 1972, caracterizada por la radicalización del discurso y el despliegue de nuevas prácticas políticas, educativas y editoriales que rebasaron los contornos de

\footnotetext{
${ }^{3}$ Información consultada en la sección "Iglesia y Sociedad en América Latina" de los tres primeros números de $C y S$ correspondientes al año 1963.
} 
las iglesias institucionales. Y finalmente, una última etapa entre 1972 y 1975, de repliegue y clausura del movimiento ante el avance de dictaduras en la región.

La revista $C y S$ comienza a publicarse en 1963 como principal órgano de difusión ISAL. Expresó las apuestas políticas e intelectuales del colectivo al tiempo que permitió definir la identidad del grupo y posicionarse tanto dentro del cristianismo como del mundo de las izquierdas. El primer consejo editorial entre 1963 y 1965 estuvo encabezado por Julio de Santa Ana como Editor Responsable e Hiber Conteris como Secretario de Redacción. La Junta Editorial estuvo conformada en este período por Julio Rubén Sabanes, Waldo A. César, Orlando Fals Borda, Mauricio López, Richard Shaull y Rafael Cepeda. ${ }^{4}$

ISAL en tanto movimiento del protestantismo latinoamericano se inscribió en lo que Michael Löwy (48) definió como "cristianismo liberacionista". Esto es, un conjunto de movimientos de cristianos (tanto católicos como protestantes) que se afiliaron a las luchas políticas de las izquierdas en los años sesenta y setenta de América Latina. Como señala Jean-Pierre Bastian (232), en la segunda mitad del siglo XX se perciben distanciamientos de la herencia liberal del protestantismo decimonónico en experiencias que buscaban dialogar con tradiciones de izquierda y movimientos políticos seculares. Esto implicaba romper con prácticas religiosas aisladas de lo social y concebir nuevas formas de acción cristiana respecto del Estado y la política. Allí donde ciertos sectores más conservadores del protestantismo proponían una lectura literal de la Biblia, los planteos teológicos impulsados por ISAL reponían una lectura contextual que implicaba la comprensión de la "encarnación” de Dios en la historia de los hombres. Por tanto, aquellas prácticas religiosas asociados a la vida interna en las iglesias les resultaban limitantes a la hora de desplegar su acción como cristianos.

${ }^{4}$ Julio de Santa Ana e Hiber Conteris eran miembros de la iglesia metodista de Montevideo. Julio Rubén Sabanes y Mauricio López eran pastores argentinos, el primero metodista de Buenos Aires y el segundo perteneciente a la Iglesia de los Hermanos Libres en la región de Cuyo. Waldo César, miembro de la iglesia presbiteriana de Brasil. Orlando Fals Borda, vinculado al calvinismo de Colombia. Richard Shaull de Estados Unidos y Rafael Cepeda de la Iglesia Presbiteriana de Cuba. 
En las "Palabras preliminares" del primer número, el equipo editorial sostenía que nacía "una revista anhelada por los evangélicos latinoamericanos que se preocupan por los problemas que plantea la sociedad que integran a la fe cristiana y a su testimonio en el mundo" (Palabras preliminares 1). En un apartado subsiguiente aparece explicitado el "punto de vista" de la revista. Argumentaban que la decisión del nombre de la revista se debía a la necesidad de expresar a Cristo como "único compromiso posible" en la "hora revolucionaria" que vivía el continente. De esta manera, apostaban a la conjunción entre religión y política al tiempo que se adelantaban a las objeciones de ciertos sectores de las comunidades evangélicas que veían a ISAL como una experiencia separada de la vida institucional de las iglesias y como espacio de politización. De allí la necesidad de reforzar el carácter cristiano de la apuesta que emprendían:

la fe cristiana es nuestro punto de vista [...] no hay desacuerdos en este punto, y deseamos que el lector lo comprenda desde el principio [...] Como hombres de nuestro tiempo, como ciudadanos de América Latina, pero sobre todo como cristianos, nos resistimos a quedar relegados en esta hora revolucionaria que vive el continente [...] Hay una ubicación cristiana que supera todos los extremos, que implica la conciliación armónica de las posiciones extremas y rescata los valores inmanentes en cada uno de esos puntos de vista. Ese es nuestro punto de vista, CRISTO es nuestro punto de vista.

El "primer umbral de secularización" a fines de siglo XIX habían configurado una separación entre la esfera doméstica y la esfera pública en materia religiosa, los principios liberales establecían que la religión quedase confinada al ámbito doméstico alejada de la vida civil y política (Di Stefano 10). La apuesta por "desprivatizar" la vida religiosa y ejercer el cristianismo en otras esferas de la vida social supuso un quiebre en esta tradición incorporada en la vida eclesiástica de las comunidades protestantes. Como señala José Zanca (200) para el caso del Centro 
de Cultura Católica en la Argentina de la década de 1920, el ejercicio de prácticas sociales más allá de la esfera privada para profesar la fe no significó necesariamente una reversión del proceso de secularización de la sociedad. Por el contrario, las prácticas desarrolladas por esos creyentes favorecieron el proceso de secularización al interior de sus propias comunidades al transformar las relaciones entre laicos y sacerdotes. Estos cristianos buscaban ejercer su catolicismo en espacios autónomos del control clerical o eclesiástico, espacios de sociabilidad con reglas seculares, como la prensa o la formación universitaria moderna. Los protestantes del ISAL realizaron la misma operación de desplazamiento del control de las autoridades eclesiásticas y desarrollo de prácticas con reglas autónomas en el marco de un proceso de secularización. El vínculo del movimiento de ISAL con las distintas “denominaciones" -a saber, las instituciones eclesiásticas metodistas, anglicanas, presbiterianas, etc.- fue uno de los grandes ejes de discusión y tensión en este período. ${ }^{5}$

A partir de 1966, las discusiones teológicas y políticas que se van a suceder al interior de ISAL respecto de la denominada "teología de la revolución" van a llevar a posicionamientos a favor de la participación en experiencias políticas ya sean en los "frentes de masas" de los partidos de izquierda o bien en organizaciones armadas. ${ }^{6}$ Por ejemplo, en Chile participaron del movimiento Cristianos por el Socialismo (1970-1973). En Bolivia, integraron las denominadas guerrillas de Teoponte, que en julio de 1970 se organizaron en apoyo al alzamiento militar del General Torres y tejieron fuertes vínculos con sindicatos del sector minero. En Brasil, los referentes de ISAL estaban asociados al Centro Ecuménico de Documentación e Información (CEDI) en Sao Paulo que fue un importante espacio de resistencia contra la dictadura. En Argentina, referentes de ISAL estuvieron vinculados con las tendencias revolucionarias del peronismo a inicios de los años

5 Véase en CyS el número 6 de 1964 "La iglesia en revolución” y el número 16-17 de 1968 "La muerte de la iglesia y el futuro del hombre". Asimismo, un texto fundamental para comprender esta tensión es: Castro, Emilio (1969) "Las denominaciones y los movimientos", en Cuadernos de Marcha $\mathrm{N}^{\circ} 29$, p. 25-32.

6 Para profundizar sobre "teología de la revolución" véanse los artículos de Richard Shaull en el número 12 de CyS de 1966 y el de Rubem Alves en el número 26-27 de 1971. 
CATEDRAL TOMADA: Revista de crítica literaria latinoamericana / Journal of Latin American Literary Criticism Cristianismo y Sociedad (1963-1973). Protestantismo de izquierda en la historia reciente de América Latina.

setenta. Y en Uruguay, algunos miembros se vincularon al Movimiento de Liberación Nacional-Tupamaros aunque mayoritariamente su participación puede registrarse en la construcción del Frente Amplio como nuevo partido político nacional. $^{7}$

En este período, el consejo editorial incorporó a Julio Barreiro (1922-2005) como Secretario de Redacción. Era un abogado y reconocido miembro de la iglesia metodista de Montevideo desde su juventud. Fue designado como Secretario de Publicaciones de ISAL al regreso de sus estudios de posgrado en Francia en 1965 donde se especializó en Ciencias Políticas. Barreiro además tenía una vasta experiencia en revistas del protestantismo por haber sido director durante la década del cuarenta del periódico metodista La Idea y luego de la revista para la infancia evangélica Arco Iris durante los años cincuenta. La junta editorial seguía conformada por Julio de Santa Ana (como presidente), Julio Rubén Sabanes, Waldo A. César, Orlando Fals Borda, Mauricio López y Richard Shaull. Sin embargo, Hiber Conteris ya no figuraba como parte de esta dado que obtuvo una beca del CMI para realizar estudios de posgrado en Paris (Roldán 59).

Hacia el año 1972, el grupo de ISAL comienza a sufrir las consecuencias del creciente autoritarismo de gobiernos de la región. Muchos de sus miembros fueron perseguidos y encarcelados como fue el caso de Hiber Conteris; otros se vieron obligados al exilio como Julio de Santa Ana que trasladó a la sede del CMI en Ginebra; y otros fueron desaparecidos, como Mauricio López, secuestrado por un grupo de tareas de las fuerzas armadas argentinas en enero 1977. En el caso de Julio Barreiro, fue perseguido, encarcelado y separado de su cargo en la Universidad de la República en el año 1973 por lo que decidió exiliarse en Buenos Aires. De este modo, la revista se trasladó con él y comenzó a ser editada bajo el sello editorial de Tierra Nueva hasta el año 1980. En este período, Barreiro ocupó el cargo de Director de la revista acompañado por un Consejo de Redacción que

7 Sobre la participación de ISAL en distintos movimientos políticos de América Latina puede consultarse la entrevista de Cervantes-Ortiz Leopoldo "En los 50 años de ISAL: Entrevista a Julio de Santa Ana”, Agencia Latinoamericana y Caribeña de Comunicación, 2 de diciembre de 2011. 
integraban Hugo Assmann, José Miguez Bonino, Eduardo Arellano, Raúl Macín y Luis Rivera. ${ }^{8}$ Desde Buenos Aires, Julio Barreiro se aseguró de confirmar a las autoridades uruguayas que ISAL había sido disuelta como organización oficialmente en 1975. En este sentido, cabe decir que $C y S$ trascendió a la propia organización y perduró como revista en el cono sur hasta 1980 cuando se prohíbe su circulación en Buenos Aires.

\section{La materialidad de $C y S$ : diseño, producción y circulación}

Abordar una revista como objeto de investigación en sí mismo exige necesariamente considerar aspectos materiales relativos a su diseño, modos de distribución, incorporación de imágenes, cantidad de páginas, lugares de impresión, formas de financiación, entre otros. Ahora bien, "advertir su densa materialidad equivale a descubrir una dimensión que excede en mucho su consideración como meros vehículos de textos e imágenes" (Delgado, Mailhe y Rogers 8). Las revistas no son meros contenedores de ideas, sino que definen también formas de producción, circulación y prácticas de lectura. En este apartado, se describen aspectos materiales de $C y S$ y se sostiene que su forma estaba asociada a un proyecto editorial de escala regional que suponía lectores evangélicos comprometidos e interesados en recibir análisis actualizados sobre los procesos políticos en los que participaban otros cristianos en distintos países de América Latina, como así también textos elaborados por reconocidos intelectuales e especialistas en temáticas sociológicas para utilizarlos como materiales de estudio para en grupos de base asociados a ISAL.

La revista estaba diseñada en un formato pequeño, sus dimensiones de aproximadamente $22 \mathrm{~cm}$ de alto por $17 \mathrm{~cm}$ de ancho fueron constantes a lo largo del tiempo. Asimismo, era un formato flexible ya que la tapa tenía un gramaje

\footnotetext{
${ }^{8}$ En 1975 se incorporan Pedro Negre Rigol, Paulo Ayres Mattos, Adolfo Ham, Miguel Cocco. Y en 1978, Zwinglio Díaz.
} 
levemente superior a las hojas internas lo que permitía su doblado. Cada número de la revista podría contener alrededor de 90 páginas, aunque también se publicaron ediciones dobles de 120 o 140 páginas. De todos modos, su espesor no era de consideración lo que facilitaba su manipulación. $C y S$ se enunciaba de frecuencia cuatrimestral, en promedio lograba publicar tres números anuales. Durante la primera época, hasta el año 1973, se logró publicar 38 números lo que evidencia una vasta y sostenida producción. Es posible inferir que estas características de formato la emparentaban más a un objeto para el estudio -se podía doblar, rayar y compartir con otros- que un objeto para atesorar en la biblioteca. ${ }^{9}$

Cada número estaba integrado por una serie de secciones que se mantuvieron relativamente estables a lo largo de la primera época. En la mayoría de los casos se iniciaba con una nota editorial. Seguidamente había una sección dedicada a reflexiones o planteos teológicos y otra, a albergar estudios de actualidad regional e internacional que muchas veces era enunciado en tapa. Los números finalizaban con una sección denominada "Iglesia y Sociedad en América Latina" en la que se recopilaba información organizativa de ISAL y una sección bibliográfica con reseñas de libros. A partir de 1970, se mantienen tres secciones básicas, aunque sin nomenclatura: un espacio editorial de páginas breves, una sección de artículos sobre un tema específico y una sección de documentos donde se transcriben informes de distintas organizaciones ecuménicas a nivel regional.

No hay presencia de publicidades comerciales al interior de la revista, aunque sí algunos avisos con referencias a nuevos lanzamientos de entidades similares como la revista católica Víspera (1967-1973) o información sobre documentos del CIDOC (Centro Intercultural de Documentación) dirigido por Iván Illich en Cuernavaca, México. A partir de 1970, comienzan a aparecer publicidades de la editorial Tierra Nueva que nace como proyecto en el seno de la Secretaría de

\footnotetext{
${ }^{9}$ En varios ejemplares consultados en distintas bibliotecas se han identificado marcas de lectores en los textos con subrayados y anotaciones a los márgenes lo que aporta indicios a este tipo de uso asociado a una lectura de formación.
} 
Publicaciones de ISAL en 1969 pero que busca trascender la comunidad de lectores evangélicos.

Una característica visual muy distintiva de $C y S$ era que tapa y contratapa presentaban colores fuertes que variaban en cada número. En contraste sobre esos fondos de colores, aparecía en negro y blanco el nombre de la revista en el encabezado junto a una cruz que se sostuvieron siempre en tapa como marca de identidad. En la solapa de la tapa aparecían los datos de redacción y los índices en la primera hoja. Además, algunos números presentaban un sumario de temas o artículos principales en tapa o en contratapa. En su interior, la revista era en blanco y negro. En general, los artículos podían estar acompañados de fotomontajes, fotografías y/o dibujos, aunque mayormente predominaba la presencia de lo textual.

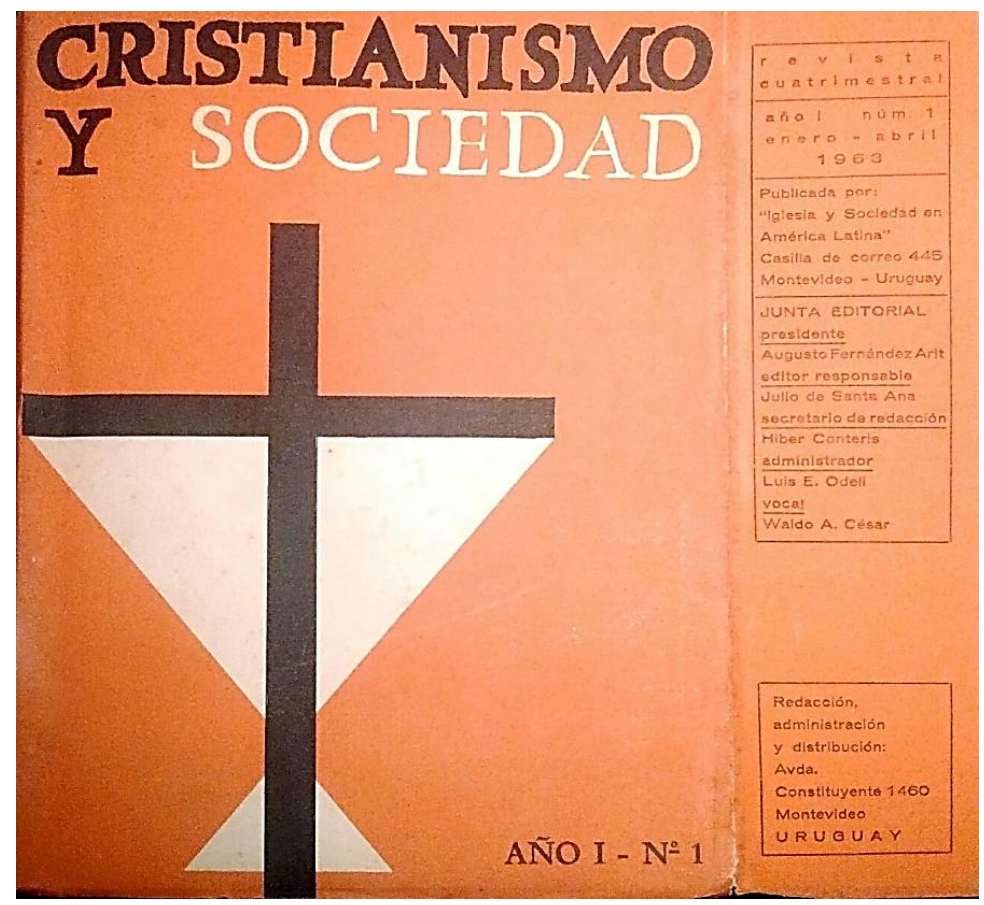

Ilustración 1. Tapa y solapa del primer número de CyS de 1963.

A partir del año 1970, se nota un cambio estético importante con la incorporación de Horacio Añón (Montevideo, 1940) como diseñador de tapas de la 
revista, quien también se encargaba de las tapas los libros de Editorial Tierra Nueva. La producción de Añón es reconocida en muchas iniciativas editoriales uruguayas de la década del sesenta como los fascículos coleccionables de Nuestra Tierra (1969-1970) y la serie Los Departamentos (1970). Sobre la base de escasos recursos técnicos y una tipografía limitada daba importancia a la variedad de tamaños y colores. Como afirma el curador Rodolfo Fuentes, en Añón se destacaban "sus naranjas y rojos mates, sus verdes secos y colores tierra, los ritmos de imágenes que se repiten para ser otra imagen, los textos, donde la tipografía es clara, potente y no plantea jamás problemas de legibilidad..." (citado en Rocca).

De este modo en las tapas de $C y S$ persistieron los contrastes de colores fuertes y la presencia principal de la cruz, pero ahora reforzados por elementos típicos de la estética de Añón como la repetición seriada de una imagen en diferentes escalas. La jerarquía de la cruz en la tapa de la revista, en reemplazo de cualquier título o contenido específico, connotaba la centralidad de la fe en tipo de intervención que promovían los protestantes de ISAL en el escenario político las izquierdas. Como sostenían en el editorial del primer número, "Cristo [era su] punto de vista”, allí estaba su eje central y de allí partía su conjunción con la sociedad.
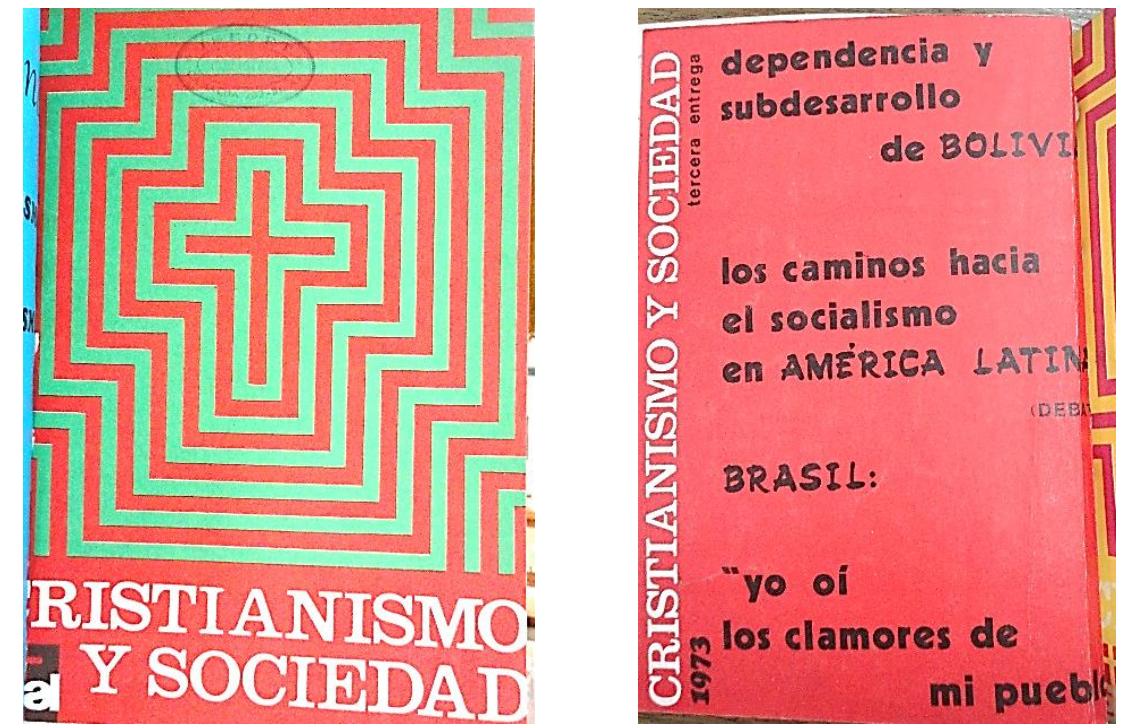

Figura 2. Tapa y contratapa de CyS N³7 (1973) con el diseño de Horacio Añón 
Como ya se ha comentado, la primera etapa $C y S$, fue editada desde la sede central de ISAL entre 1963 y 1973 en la ciudad de Montevideo (Uruguay). A partir del exilio de Julio Barreiro, secretario de redacción desde 1967, fue editada desde la ciudad de Buenos Aires (Argentina) bajo el sello de la editorial Tierra Nueva. No se han conseguido datos respecto del números de ejemplares impresos por tirada, aunque se estima tuvo que ser considerable dado el alcance geográfico de la distribución. En cuanto a la impresión, entre 1963 y 1967 se realizó en Talleres Gráficos Emecé en Montevideo. Pero entre 1968 y 1973, la revista fue impresa por la Comunidad del Sur, una experiencia de sociabilidad política y familiar emprendida por anarquistas.

En cuanto a la circulación, $C y S$ se distribuía en más de catorce países en toda Latinoamérica a través de una red de agentes y librerías vinculadas al protestantismo: Librería "La Aurora” en Argentina y Uruguay; Impresa Methodista y Librería Internacional en Sao Paulo (Brasil); Librería La Reforma en Puerto Rico, Librería Luz y Verdad en Lima; Librería El Sembrador y El Lucero en Santiago de Chile; Librería Odell en Matanzas (Cuba); Casa Unida de Publicaciones (CUPSA) en ciudad de México, Librería Dominica en República Dominicana, Librería Senderos en Venezuela. Así como también venta directa a través de representantes de ISAL: Gerardo Pet en Bolivia, Reverendo Jaime Goff en Colombia y Alvaro Ramos en Bogotá, Waldo César en Brasil, reverendo Marcelo Pérez Rivas en San José de Costa Rica, Miguel Calvetti y Rev. Gonzalo Carvajal en Ecuador, Benjamín Monterroso en Guatemala y Reverendo Simón Alvaralo en Panamá.

Si bien es posible estimar que ISAL recibía apoyo financiero desde el CMI para llevar adelante sus proyectos a escala regional, $C y S$ apelaba directamente a sus lectores para que se suscriban a la revista. Así lo expresaban en las páginas finales de varios ejemplares: "Cristianismo y Sociedad necesita imperativamente obtener el decidido apoyo de los cristianos latinoamericanos que se interesen por el tema de la responsabilidad social cristiana". El precio en los primeros años equivalía a un dólar norteamericano por ejemplar; mientras a inicio de la década del setenta se 
podía suscribir por correo postal aéreo 4 números por el precio de diez dólares. Más allá del valor de mercado, cabe considerar que las comunidades protestantes a las que se direccionaba la revista pertenecían mayoritariamente a capas medias y altas de las ciudades latinoamericanas. Ni artículo de lujo ni una producción de alcance masivo, es posible inferir que la revista era comprada por lectores asociados a clases medias urbanas, profesionales e ilustradas, sector característico de las comunidades protestantes históricas.

\section{Política editorial en la conjunción de lo religioso y lo social}

Desde el primer número, $C y S$ expresaba la intención de ofrecer a sus lectores textos especializados sobre la situación política, económica y social de América Latina como modo de estimular a los cristianos evangélicos a conocer los problemas que enfrentaba la cambiante sociedad latinoamericana. En las palabras preliminares que introducen el primer número, los redactores de $C y S$ sostenían que la fe cristiana implicaba creer en la encarnación de Dios en la historia humana, esto es, entender la historia secular como parte de la voluntad creadora. Por lo tanto, los cristianos debían hacer un esfuerzo para comprender lo que estaba sucediendo en sus países, identificar la acción divina en dichos procesos y desde allí participar activamente al servicio de los hombres en América Latina como expresión del espíritu de Cristo ("Palabras preliminares” 3).

El propio nombre de la revista daba cuenta de la característica de la política editorial: asociar religión y sociedad a través de un conjunto nutrido de textos que permitieran a los protestantes sumarse a los "rápidos cambios sociales" que vivía el continente. Como se explicó en el primer apartado, a fines de la década del cincuenta el CMI había desarrollado una serie de investigaciones que recopilaban diversas mudanzas sociales a escala global y desde donde impulsaba la conformación de grupos regionales de acción ecuménica como lo fue ISAL. Cambios demográficos, procesos políticos y avances productivos eran señalados - 
entre otros- como parte de una dinámica de aceleración de la historia humana que los cristianos tenían el deber de comprender para intervenir.

ISAL desarrolló esta tarea de formación intelectual y participación política en distintos encuentros presenciales denominados "consultas" y a través de las páginas de la revista que constituyó una plataforma de circulación de los debates y problemas. Desde la revista se convocaba a enviar dos tipos de contribuciones: o bien, aquellas vinculas a temáticas estrictamente religiosas como "problemas de la misión cristiana frente a la estructura social de América Latina; sociología religiosa latinoamericana; teología de los problemas que conciernen a Iglesia y Sociedad, etc" ("Palabras preliminares" 4); o bien, contribuciones asociadas a estudios sociológicos, económicos y políticos de la realidad de la región.

Asimismo, en la conjunción de lo religioso y lo social, $C y S$ inscribía su línea editorial a sabiendas de que dialogaba con sectores no cristianos -y con otras revistas del mundo secular-, pero desde un sesgo religioso propio que reivindicaban. Así lo expresaban en el editorial del tercer número de 1963:

CRISTIANISMO Y SOCIEDAD ha logrado captar el problema fundamental del "aquí y ahora" en que vivimos y en este sentido ha entrado en la corriente de publicaciones que desde diferentes ángulos y respaldadas en diversas ideologías intentan dilucidar, explicar, el problema latinoamericano, señalar las dificultades básicas del subdesarrollo y trazar los planes para una nueva sociedad. Es una grata comprobación. ¿Pero qué más? ¿Qué hay de nuevo- frente al panorama total de estas publicaciones- en las páginas de CRISTIANISMO Y SOCIEDAD? ¿Cuál es la nota, el énfasis, el acento particular que nos distingue? ¿Existe en realidad este acento? Algo de eso es lo que hemos querido expresar al insertar en esta primera página el grabado de Hodgell. Nuestra preocupación respecto al mundo latinoamericano es común a otras posiciones y a otras ideologías; nuestros artículos se les parecen; las soluciones que ellos y nosotros propugnamos tienen mucho de 
compartido. Pero nuestro acento propio está, sin embargo, en las dos manos como copas, en la tensión del rostro, elevados al cielo. Ninguna transformación fundamental vendrá que no venga de allí. Es la convicción más profunda de los que hacemos esta revista, el ancla segura de nuestra esperanza. ("Editorial” 1)

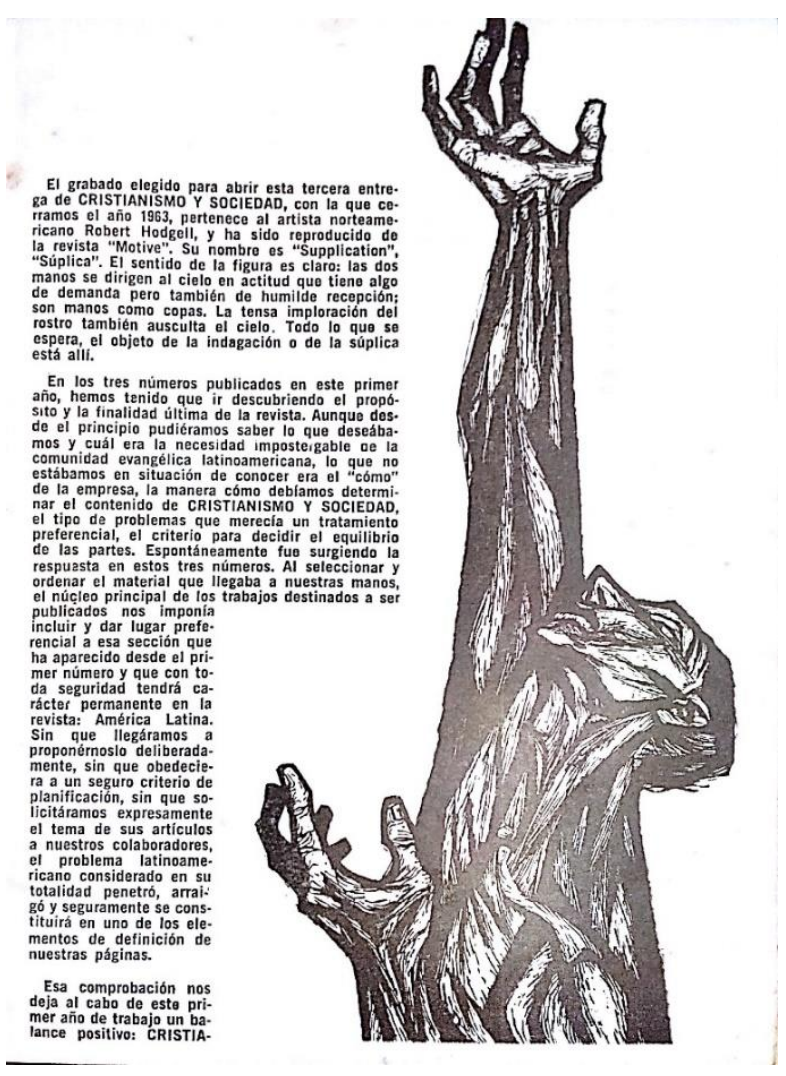

Figura 3. Reproducción del grabado del norteamericano Robert Hodgell en el editorial del n³ de 1963.

A partir del quinto número de $C y S$, las tapas presentaron un sumario que anticipaba a los lectores el contenido de la sección central de cada número. Una recopilación de algunos de dichos títulos permite dar cuenta del amplio abanico de temas desplegados en las páginas de la revista: $\mathrm{N}^{\circ} 6$ (1964) "La iglesia en revolución"; N7 (1965) "Pensamiento Cristiano y situación contemporánea"; No8 (1965) "Diálogo de nuestro tiempo: cristianismo y marxismo"; N¹3 (1967) "La 
influencia de los Estados Unidos en América Latina"; №14 (1967) "El servicio social en América Latina"; N¹5 (1968) "Migraciones en América Latina"; N²0 (1969) "La nueva izquierda en los Estados Unidos, El ecumenismo en México, Manifiesto Negro: los negros norteamericanos reclaman la toma del poder”; №2627 (1971) "Teología y Liberación"; N³5-36 (1973) "Peronismo y socialismo"; No37 (1973) "Dependencia y subdesarrollo de Bolivia / Los caminos hacia el socialismo en América Latina. / Brasil: yo oí los clamores de mi pueblo"; N³8 (1973) "México 72”.

Cada uno de los tres números promedio que se editaba por año de $C y S$ incluía un editorial, un conjunto de artículos de "planteo teológico", una sección en diálogo con las ciencias sociales y secciones finales compuestas por documentos, reseñas de libros y eventos de ISAL. Como es posible observar, los sumarios delimitaban una agenda temática que vinculaba cristianismo, política y problemas sociales en una perspectiva transnacional que ponía en diálogo coyunturas locales de distintos países de la región. Revolución, desarrollo, migraciones, dependencia, nueva izquierda, marxismo fueron algunos de los tópicos utilizados reiteradamente. Era persistente la vocación de conjugar sus reflexiones teológicas con otras corrientes de pensamiento (en particular, el marxismo) y con colaboraciones de destacados intelectuales pertenecientes al campo de las ciencias sociales latinoamericanas.

En esta línea es posible reconocer dos grandes conjuntos de autores presentes en las páginas de $C y S$ que dan cuenta de una política editorial donde se conjuga lo religioso y lo social. Por un lado, un conjunto de autores conformado por teólogos ya sean católicos o protestantes que aportaron ensayos bíblicos, análisis de la situación de las iglesias evangélicas latinoamericanas y planteos sobre la participación política de los cristianos en distintos escenarios locales y globales. Por otro lado, aquellos intelectuales del mundo secular, especialistas en distintas áreas de interés para los integrantes de ISAL como reforma agraria, migraciones, servicio social, desarrollo urbano, educación de adultos, entre otros. 
Entre los primeros podemos destacar a quienes desde las páginas de $C y S$ contribuyeron a formar el campo de la teología de la liberación latinoamericana: Carlos Gattinoni (pastor metodista argentino), Emilio Castro (pastor metodista uruguayo), Federico Pagura (pastor metodista argentino), Hugo Assmann (teólogo católico brasileño), Gustavo Gutiérrez (teólogo católico peruano), Juan Luis Segundo (teólogo jesuita uruguayo) y José Miguez Bonino (teólogo metodista argentino), entre los más reconocidos a escala regional.

Asimismo, publicaron artículos referentes teológicos norteamericanos y europeos asociados a respectivas luchas civiles y políticas en sus países e interpelados también por las discusiones del "tercer mundo": Richard Shaull (teólogo presbiteriano norteamericano), André Dumas (teólogo y politólogo francés), Jurgen Moltmann (teólogo protestante alemán), y hasta el propio Martin Luther King Jr. (pastor bautista norteamericano).

En cuanto a los intelectuales seculares es posible identificar referentes de las ciencias sociales y el pensamiento latinoamericano a los que los protestantes de ISAL recurrieron en una estrategia de confluencia con sectores del campo progresista. Esta confluencia es evidencia además del proceso de secularización en el que estaban inmersos los protestantes en la medida en que los saberes legítimos para la intervención como cristianos en el mundo ya no provenían de exégesis exclusivamente bíblicas ni de la autorización del poder eclesiástico. El intercambio con intelectuales provenientes de un mundo externo al confesional, con reglas e instituciones específicas, les permitía ganar autonomía respecto de la regulación de las autoridades religiosas.

Entre los intelectuales y especialistas que participaron como autores en $C y S$ se pueden mencionar a: Carlos Real de Azúa (iniciador de la ciencia política en Uruguay), Celso Furtado (economista brasileño representante del desarrollismo de la CEPAL), Ezequiel Ander-Egg (sociólogo argentino referente del campo del trabajo social), Gino Germani (referente de la sociología argentina), Orlando Fals Borda (sociólogo colombiano referente de la investigación acción-participativa), Paulo Freire (pedagogo brasileño autor de la Pedagogía del Oprimido), Pierre 
Furter (filósofo suizo especializado en educación), Rodolfo Puiggrós (historiador argentino referente de la intelectualidad peronista de izquierda).

Cabe señalar el lugar destacado que tuvo la pedagogía de Paulo Freire en sus páginas, siendo $C y S$ una de las primeras plataformas de difusión en castellano del pedagogo a fines de los sesenta (Brugaletta 22). En el mes de octubre de 1968, fue publicado un suplemento especial de la revista bajo el título "Contribución al proceso de concientización en América Latina”. El material era presentado como una edición no comercial reservada para uso interno y exclusivo de ISAL y los subscriptores protestantes. Compilaba varios textos de Paulo Freire como así también de otros colegas residentes en Chile como Raúl Velozo Farías, José Luis Fiori, Ernani María Fiori y Jorge Mellado que oficiaba de traductor del portugués al español. Algunos de estos textos fueron luego parte del libro Pedagogía del Oprimido, editado por primera vez en castellano en 1970 por la editorial protestante Tierra Nueva en Montevideo. El interés por los aportes de la pedagogía freireana a los procesos de "concientización" era explicitado de la siguiente manera en la editorial correspondiente al número 16-17 de 1968:

Estamos convencidos en ISAL, de la necesidad de trabajar cada vez en mayor profundidad y en mayor extensión, en el proceso de concientización del hombre latinoamericano, preparándolo para "un nuevo mañana" que se producirá tras un doloroso y prolongado alumbramiento. En efecto, América Latina parece destinada todavía a tener que soportar un largo cautiverio, pero mientras nuestros pueblos sufren y esperan, nadie puede quedarse dormido. Hay que velar y hay que luchar, día tras día, hora tras hora, usando todos los medios que tengamos a nuestro alcance, para ir creando y afirmando condiciones que hagan posible la liberación total de la humanidad latinoamericana. ("Editorial" 1)

Los lectores protestantes de $C y S$ eran convocados a formar parte de un proceso social que aparecía muchas veces representado como inmediato e 
inexorable. La "hora revolucionaria" del continente parecía teñirlo todo, por lo tanto, la responsabilidad cristiana debía traducirse en acción directa en la participación política tanto en frentes de masas de movimientos políticos populares y de izquierda como así también en experiencias de lucha armada (Conteris 1). Los cambios eran representados como inminentes, aunque no expresaban certezas de su dirección. De todos modos, desde la revista se reforzaba una clara apuesta a favor de los movimientos de liberación. El editorial del número 22 de 1970 resulta revelador para dar cuenta de los horizontes de expectativas al inicio de la década:

Entre los pensadores más lúcidos de América Latina, ya son muchos los que anuncian que la década del 70, será la de la liberación de nuestro continente o no será nada. Si la nada no existe, entonces esta década, suponiendo la hipótesis contraria, será el caos, la desesperación, la anarquía, la opresión en sus grados más infames. No es ahora el momento de entrar a analizar los múltiples aspectos que sostienen los pronunciamientos de quienes anuncian la liberación de nuestros pueblos para fechas no muy lejanas. Más bien, para los cristianos, esta hora es de tal gravedad que nos obliga a plantearnos la pregunta con la cual abrimos esta nueva entrega de CRISTIANISMO Y SOCIEDAD, es que, a la vez, la primera entrega de la década: ¿LA IGLESIA, PARA QUÉ? [...] La Iglesia para la liberación del hombre latinoamericano, por amor a Cristo, por amor a todo aquel que sufra. (Iglesia 1)

Los pronósticos desalentadores no tardaron en confirmarse. El año 1973 fue un punto de inflexión importante para la historia del continente y de la revista en particular. Los golpes de Estado en Chile y en Uruguay corroboraron el avance de las derechas en el cono sur. En relación con los integrantes de ISAL y de CyS en Montevideo, al menos desde el año 1968 fueron vigilados y perseguidos por parte 
de las fuerzas de seguridad del gobierno uruguayo. ${ }^{10}$ En abril de 1972, como represalia a una acción armada de MLN-Tupamaros que los grupos paramilitares asociaron a integrantes de ISAL, la puerta de la Iglesia Metodista de Montevideo donde funcionaba la sede editorial fue detonada con un artefacto explosivo.

A posteriori de este acontecimiento, Julio Barreiro -quien estaba a cargo de la edición de la revista- fue encarcelado y separado de su cargo en la Universidad de la República, y una vez liberado decidió exiliarse en Argentina. Buenos Aires parecía contraponerse a este clima de autoritarismo de los países de la región y allí decidió trasladarse el director junto a la revista iniciándose la segunda etapa de la publicación. Sin embargo, pocos años después, el autoritarismo se evidenció también en la capital argentina como expresaba el editorial del número 40-41 impreso allí bajo el sugerente título de resonancias leninistas “¿Qué hacer?”:

¿Qué hacer, frente al avasallante impulso que han tomado las empresas multinacionales en nuestros países? [...] ¿Qué hacer, frente a la presencia que será irreversible, por varias décadas, de los ejércitos actuando en la vida política de nuestros pueblos? ¿Qué hacer, frente a las brutales violaciones de los Derechos Humanos que estamos viviendo todos los días y de las más diversas maneras en nuestros países? ¿Qué hacer, en cuanto al papel que deben jugar las Iglesias Cristianas, que ya han sido señaladas por la represión, en casi todos nuestros países, a medida que sus congregaciones, episcopados, movimientos y organizaciones han ido tomando cada vez mayor conciencia política frente a toda esa situación? ¿Qué hacer, por último, en cuanto a nuestra responsabilidad como pueblo y para con nuestros pueblos, cuando la orden de mando de todos los esquemas de dominación que vuelven a afligirnos es la desmovilización de todas las organizaciones populares? [...] no podemos detenernos, como tampoco podemos dejar de ser realistas. Nuevamente, la reflexión y las

\footnotetext{
${ }^{10}$ Según consta en documentos de la Dirección Nacional de Información e Inteligencia (DNII) de la Policía de Montevideo consultados por el autor.
} 
exigencias teóricas nos exigen toda nuestra atención, para reorganizar nuestra lucha por la liberación. (“Editorial” 1)

La primera época de CyS finalizó en 1973 con las últimas ediciones realizadas desde Montevideo. En el año 1975, el agrupamiento ISAL fue disuelto formalmente como estrategia para que las autoridades uruguayas desistan de la persecución de sus miembros muchos de los cuales ya se encontraban en el exilio. La segunda época de $C y S$ se inició entonces en 1974 desde la ciudad de Buenos Aires como publicación de editorial Tierra Nueva y permaneció allí hasta el año 1980 cuando la dictadura argentina decidió prohibir su circulación. ${ }^{11}$

\section{Reflexiones finales}

En este artículo se caracterizó a la revista $C y S$ como una publicación periódica producida por ISAL que no sólo expresó la opinión e intereses de este particular agrupamiento político religioso, sino que contribuyó a conformar un protestantismo de izquierda en la historia reciente de América Latina en el marco de un proceso social más amplio de radicalización de la vida cultural y política del continente. Como se señaló, CyS se inscribía en dos tradiciones de publicaciones periódicas latinoamericanas: una asociada a la prensa protestante en la larga duración y otra, en la coyuntura de los sesenta, emparentada a las publicaciones políticas y culturales de la nueva izquierda. En ambas tradiciones $C y S$ se distingue y tensiona: disrumpe con una prédica de izquierda en el campo religioso al mismo tiempo que se posiciona con proclamas teológicas en el terreno de las izquierdas.

El propio nombre de la revista daba cuenta de su política editorial distintiva: conjugar religión y sociedad como modo de expresar la "responsabilidad de los

${ }^{11}$ Si bien el análisis de la segunda etapa de $C y S$ en Buenos Aires no es objeto de este artículo, cabe mencionar que prosiguió editando tres números al año en promedio y sosteniendo su distribución por toda América Latina. 
cristianos" en los "rápidos cambios sociales" que vivía América Latina. En los diez años comprendidos en esta primera etapa de la publicación es posible reconocer el modo progresivo en que este compromiso cristiano se fue asociando cada vez más explícitamente a los movimientos populares y de izquierda del continente al compás del proceso de radicalización política que atravesó a distintas expresiones culturales e intelectuales.

Asimismo, CyS como expresión del protestantismo de izquierda representado en ISAL, se inscribió en el proceso de secularización de las sociedades occidentales. Tanto la conformación de los consejos editoriales de la revista, como los discursos y vínculos que desde allí se desplegaron, dan cuenta del grado de autonomía que estos protestantes habían logrado respecto a la regulación por parte de las autoridades religiosas. Volcados a la discusión de los debates propios del mundo secular y compartiendo con los intelectuales seculares de la región diagnósticos y programas de acción, los protestantes de $C y S$ revindicaron un modo cristiano de participar en la "hora revolucionaria" que vivía el continente.

\section{Bibliografía}

AAVV. "Palabras preliminares", en Cristianismo y Sociedad, año 1, nº1 (1963): $1-4$. . "Editorial", en Cristianismo y Sociedad, año I, n³ (1963): 1-2. . "Editorial”, en Cristianismo y Sociedad, año VI, n¹6-17 (1968): 1-2. . “La Iglesia, ¿para qué?”, en Cristianismo y Sociedad, año VIII, n²2 (1970): 1-2.

. "Editorial", en Cristianismo y Sociedad, año XII, n40-41 (1974): 1-2

Abrecht, Paul. Las iglesias y los rápidos cambios sociales. Buenos Aires: Aurora, 1963. 
Bastian, Jean Pierre. "La mutación de los protestantismos latinoamericanos, 1961 1992”. Protestantismos y modernidad latinoamericana: Historia de unas minorías religiosas activas en América Latina. México: Fondo de Cultura Económica, 2013. 222-278.

Brugaletta, Federico. "El protestantismo y la circulación de la pedagogía de Paulo Freire en América Latina", en Paulo Freire Revista de Pedagogía Crítica, año 15, n 17 (2017): 21-40

Cameron, Euan. "Las turbulencias de la fe”. El siglo XVI. Barcelona: Crítica, 2006. 166-196.

Conteris, Hiber, “La Iglesia en revolución”, en Cristianismo y Sociedad, año II, $\mathrm{n}^{\circ} 6$ (1964): 1-2.

Delgado, Verónica. “Algunas cuestiones críticas y metodológicas en relación con el estudio de revistas”. Tramas impresas. Publicaciones periódicas argentinas $(X I X-X X)$. La Plata: Facultad de Humanidades y Ciencias de la Educación, Universidad Nacional de La Plata, 2014. 11-25.

Delgado, Verónica; Mailhe, Alejandra; Rogers, Geraldine. "Introducción". Tramas impresas. Publicaciones periódicas argentinas (XIX-XX). La Plata: Facultad de Humanidades y Ciencias de la Educación, Universidad Nacional de La Plata, 2014. 8-9.

De Vries, Egbert. El hombre en los rápidos cambios sociales. México: Casa Unida de Publicaciones, 1962.

Di Stefano, Roberto. "Por una historia de la secularización y de la laicidad en la Argentina". Quinto Sol, vol. 15, n¹ (2011): 1-32.

Gramuglio, María Teresa. "Sur. Una minoría cosmopolita en la periferia occidental". Historia de los intelectuales en América Latina. Tomo II. Los avatares de la ciudad letrada en el siglo XX, ed. Carlos Altamirano. Buenos Aires: Katz, 2010. 192-210.

Gilmont, Jean-Francois. "Reformas protestantes y lectura". Historia de la lectura en el mundo occidental. Buenos Aires: Taurus, 2011. 376-390 
Girbal-Blacha, Noemí, y Daiana Quattrocchi-Woisson. Cuando opinar es actuar. Revistas argentinas del siglo XX. Buenos Aires: Academia Nacional de Historia, 1999.

Hulsether, Mark. Building a Protestant Left: Christianity and Crisis Magazine, 1941-1993. Tennesse: University of Tennessee Press, 1999.

Lenci, María Laura, y Ana Barletta. "Politización de las Ciencias Sociales en la Argentina. Incidencia de la revista Antropología 3er. Mundo 19681973”, Sociohistórica, 8, (2000): 177-199.

Löwy, Michael. "El cristianismo liberacionista en Latinoamérica”. Guerra de dioses: religión y política en América Latina. México: Siglo XXI, 1999. 47-106.

Obermüller, Rodolfo et al. Responsabilidad social del cristiano. Guía de estudios. Montevideo: ISAL, 1964.

Paredes, Alejandro. "Publicaciones y militancia político-religiosa latinoamericana: Las redes de coautoría de Mauricio López y de Ignacio Ellacuría en las publicaciones de la editorial Tierra Nueva (década de 1970)". Cuadernos del CILHA, vol. 12, n 1 (2011): 173-92.

Pimentel, Layana Karine. "Paz e Terra: o pensamento da esquerda cristã expresso nos debates da revista (1966 a 1969)". Revista Brasileira de História das Religiões, vol. 1, n 3 (2009): 1-16.

Rocca, Thiago. "El valor de la sobriedad Añón. Un diseñador en su tiempo". Semanario Brecha. 15 de junio de 2017. Recuperado de <http://brecha.com.uy/valor-la-sobriedad/>

Roldán, F. Alberto. "Entrevista exclusiva a Hiber Conteris”. Teología y Cultura, vol. 13 (2011): 57-64.

Spivak, Daniela. Las revistas montoneras. Cómo la organización construyó su identidad a través sus publicaciones. Buenos Aires: Siglo XXI, 2015. 
CATEDRAL TomAdA: Revista de crítica literaria latinoamericana / Journal of Latin American Literary Criticism Cristianismo y Sociedad (1963-1973). Protestantismo de izquierda en la historia reciente de América Latina.

Zanca, José. "Los Cursos de Cultura Católica en los años veinte: apuntes sobre la secularización”. Prismas, Revista de historia intelectual, nº16 (2012): 199-202. 